sentence). The French authorities placed him under house arrest, operating under sweeping detention powers given to them as part of the state of emergency declared after terrorist attacks in the country.

Leaving aside the fact that Hicheur's conviction has been vigorously contested by many scientific colleagues, a fundamental legal principle in a democracy is 'double jeopardy', which says that someone cannot be tried twice for the same offence. Yet this is effectively happening to Hicheur, both in Brazil and France. Likewise, another principle is that those who have served their sentence should have the right to pursue a new life unhindered - yet Hicheur, who by all accounts was successfully making a fresh start after moving to Brazil in 2013, and contributing productively to the country's science, has been denied this chance.

Whether one agrees or disagrees with Hicheur's house arrest and many of his colleagues have denounced it as brutal, unjustified and unnecessary - at least it has a semblance of legal logic under the exceptional temporary situation in France.

That cannot be said of Hicheur's ejection from Brazil, which in the absence so far of a valid explanation seems to smack of arbitrariness linked to pre-Olympics tension and recent widespread coverage by Brazilian media of his past conviction. Moreover, the haste and circumstances of the action seem to violate Brazilian law, human rights and international treaties to which Brazil is a signatory.

The incident is all the more perplexing because Brazil's justice minister acknowledges that Hicheur was a law-abiding citizen during his time in the country, and France has not raised any new allegations against him. It is also difficult to reconcile the physicist described by his colleagues with the account of Hicheur in the French interior ministry's house-arrest order, which says there are "serious reasons" to think that he constitutes a security threat.

The reaction of Ignacio Bediaga, head of the group at the Brazilian Center for Physics Research in Rio de Janeiro where Hicheur first worked when he came to Brazil, echoes that of many of the deported

physicist's colleagues: "Hicheur performed an exceptional job, showed exemplary moral and ethical behaviour and a great willingness to collaborate with the group." He adds that at no time did anyone in the group perceive anything amiss with Hicheur's conduct.

Science allowed Hicheur, a Franco-Algerian citizen born in Algeria, to reach the heights of working on the Large Hadron Collider 'Beauty' experiment, better known as LHCb. After he became a persona non

"The haste and circumstances of the action seem to violate Brazilian law." grata in European research organizations following his conviction, his international colleagues helped to find him a place to start afresh in Brazil and continue his science.

Hicheur deserves a fair and full hearing. The best route could be the Brazilian courts, and colleagues and academics there deserve support alongside Hicheur's lawyers for their efforts to pursue the case. Were Hicheur's deportation revoked, this might open the way for his return to work in Brazil, and thus make it easier for France to lift his house arrest.

In France, Hicheur is appealing his detention. But in the current climate of fear, the judicial machinery may be harder to mobilize.

French President François Hollande and his government, in their engineering of the state-of-emergency laws, have to their credit sought a difficult balance between giving police extra powers to help them fight the terrorist threat and preserving fundamental liberties and civil rights. But there is nonetheless the risk that such measures will be misused.

And if an intelligent and articulate individual such as Hicheur (a Muslim) with a bevy of support from his scientific colleagues can find himself helpless, what then of the many others with much less capacity to defend themselves? Fairness, freedom, the rule of law and human rights - including the right to a defence - are the basis for a democracy. It is not easy in these times to defend these values, much less for someone convicted in the past of terrorism-related offences, but defend them we must.

\section{Bowled over}

\section{Assessing the contents of the toilet bowl in the name of crime prevention.}

$\mathrm{W}$ hen they flush the toilet, most people don't think about what happens next. But for several hundred students at a private university in Washington state five years ago, what happened next was that scientists spied on some of their most intimate personal details. The researchers identified times of stress, probed the ethics of the students and calculated how many of them were bending the rules by taking drugs to help them with their degrees. The students had no knowledge of this at the time. And they probably still don't.

Likewise, the citizens of dozens of European cities have no idea that their sewage is being sifted through right now, officially to protect them; or that the police are studying the results to track crime. The toilet bowl and its contents, once extremely private, are becoming very public indeed. It's called wastewater-based epidemiology. Improved sensing techniques and analysis have made the contents of sewers and waste pipes a powerful source of data. And where there are data, there are researchers. Because although people may tell lies, the urine they send down the drain rarely does. Around for a decade or so, this analysis of waste water has mostly been used to obtain information that people would prefer others did not have - their use of illegal drugs, chiefly. Drugs broken down in the body leave telltale traces of metabolites, some of which can be found, quantified and backcalculated to work out how much of the original substance was present. Combined with a reliable estimate of the number of people who have, well, contributed a sample to the sample, the analysis can offer guidance on average consumption and how it changes.

Some of the results are more worth noting than truly noteworthy. Cocaine use, unsurprisingly, peaks at the weekend. People in smaller towns and cities prefer amphetamines. And anyone watching the Netflix show Narcos - which chronicles the life and times of notorious drug lord Pablo Escobar - will be unsurprised to hear about the truly colossal amounts of cocaine that pass through the residents and into the waste water of the city of Medellín, Escobar's one-time heartland.

Even the study that involved the Washington students merely seemed to confirm what most people already accept: healthy university students take prescription-only medicines as 'smart drugs' to try to boost their cognitive abilities at exam time (D. A. Burgard et al. Sci. Tot. Environ. 450-451, 242-249; 2013).

A paper in the journal Forensic Science International this month offers an intriguing new possibility. Swiss researchers describe how they hooked up with drug-enforcement investigators to use wastewater analysis to shed light on the structure of drug markets, the criminals who controlled them, and how much influence police operations had on supply (F. Been et al. Forensic Sci. Int. 266, 215-221; 2016). The results are not foolproof - analysis of cannabis metabolites is chemically tricky, for example, and cannot distinguish between all sources - but the study did report some successes.

Heroin use in Lausanne was estimated by measuring morphine in the sewers and subtracting what was known to have been prescribed medically. Between October 2013 and December 2014, the scientists estimated that average daily consumption of pure heroin in the city was 13 grams. During the study, the police arrested two dealers, and analysis of phone records and interviews with users suggested that the dealers sold about 6 grams a day between them - about half the total market. This supported police intelligence that heroin, unlike other drugs such as methamphetamine, was supplied by a small number of local dealers who could be effectively targeted. You can flush, but you can't hide. 